\title{
Passado no presente: racismo, imprensa e imaginário
}

\author{
Juremir Machado da SILVA ${ }^{1}$
}

\begin{abstract}
Resumo:
Este texto aborda o tratamento do racismo pela imprensa no século XIX, à época da abolição da escravatura no Brasil. Trata-se também de tentar ver como esse passado se insinua no presente, atravessando os séculos como um imaginário cristalizado.
\end{abstract}

Palavras-chave: racismo; escravidão; história; Brasil; imaginário.

\section{Past in the present: racism, press and imaginary}

\begin{abstract}
:
This text addresses the treatment of racism by the press in the nineteenth century, at the time of the abolition of slavery in Brazil. It is also about trying to see how this past insinuates itself into the present, traversing the centuries like a crystallized imaginary.
\end{abstract}

Keywords: racism; slavery; history; Brazil; imaginary.

\section{Pasado en el presente: racismo, prensa e imaginario}

Resumen:

Este texto aborda el tratamiento del racismo por parte de la prensa en el siglo XIX, en la época de la abolición de la esclavitud en Brasil. Se trata también de intentar ver cómo este pasado se insinúa en el presente, atravesando los siglos como un imaginario cristalizado.

Palabras clave: racismo, esclavitud, historia, Brasil, imaginario

\section{$* * *$ \\ Enquanto a solidariedade alimenta a nossa responsabilidade, a ecologia da ação} mina-a. Com efeito, o sentido das nossas ações éticas pode ser desviado ou pervertido pelas condições do meio em que se realizam. Daí a nossa situação incerta e complexa em relação aos nossos atos: somos totalmente responsáveis por nossas palavras, escritos, ações, mas não somos responsáveis pelas interpretações deles feitas nem pelas suas consequências. Isso introduz, como vimos, a aposta e a estratégia no coração da responsabilidade.

\footnotetext{
${ }^{1}$ Professor do Programa de Pós-Graduação em Comunicação Social, da Pontifícia Universidade Católica do Rio Grande do Sul, pesquisador 1B do CNPq. Orcid: 0000-0001-8105-5596. E-mail: juremir@pucrs.br.
} 


\section{Dialógica do descobrimento}

Não há linearidade na história. Podem acontecer saltos para a frente ou recuos. Falar em evolução, por exemplo, aciona um termo controvertido em torno do qual se erguem mitos, preconceitos e expectativas frustradas. Faz pensar que o presente é necessariamente melhor do que o passado e que o futuro deverá ser melhor ainda. A história não é uma linha de trem com uma estação de chegada chamada Paraíso, Redenção, Emancipação ou Liberdade. É claro que são estabelecidos a cada época ou lugar parâmetros de mensuração de conquistas. Em sociedades onde saber ler e escrever insere na estrutura social, garantindo empregos e posições no conjunto competitivo, avanços na alfabetização contam como progressos inquestionáveis. Da mesma forma, a liberdade funciona como um critério de qualidade de vida. Não escravizar pessoas aparece como um elemento inquestionável de organização qualificada. O Brasil, que só aboliu a escravidão em 13 de maio de 1888, figurou durante mais de três séculos como um retardatário na implantação dos pilares civilizatórios básicos.

Esse é o termo consagrado: civilizatório. A palavra civilização, contudo, carrega os seus males. Pode ser usada para fazer crer que a cultura europeia, que colonizou parte do mundo a partir da primeira grande globalização, a do século XVI, é superior a outras culturas, como a dos incas, dos maias, dos astecas, etc. Culturas são modos históricos de organização social do cotidiano. Existem os mais diferentes arranjos. Seria possível fazer intermináveis citações sobre a singularidade das culturas ao longo do tempo. Em grande parte, há luta pelo poder. Quanto mais complexo o sistema, exigindo um aparelho administrativo especial, maior a disputa pelo controle do dispositivo capaz de gerir corações, mentes e recursos.

Entender o presente, dialogando com o passado, para construir um futuro melhor remete a escolhas, valores, padrões e metas. O que se pode querer? Menos desigualdade, menos exclusão, menos preconceitos, mais respeito à diversidade, diferença e pluralismo, mais oportunidades para a realização dos sonhos socialmente aceitos de cada indivíduo. Uma perspectiva radicalmente relativista poderá questionar cada termo usado até agora, enfatizando que para cada um deles pode existir num mesmo grupo social um contraponto. A pergunta que imediatamente aparece é esta: todos legítimos? Certamente que não. Pode ser legítima a ideia de reinstituir a escravidão? Pode haver alguma legitimidade na defesa do racismo? Não. A Terra não é plana, a Covid-19 não é transmitida por uma bactéria, mas por 
um vírus, o racismo não é defensável, há verdades disponíveis na praça.

Uma dialógica do descobrimento implica conversar com a vida sobre como ela se concretiza, para ver seus sentidos encobertos virem à tona. $\mathrm{O}$ racismo tem sobrevivido como um sistema de hierarquia social. A sua base argumentativa é fraudulenta. A superioridade racial é talvez a maior fake news de todos os tempos. Os fundamentos da suposta racionalidade do escravismo assentam-se em pantanosas camadas de terra infértil. O escritor José de Alencar (2009, p. 284), de imensa fama e prestígio no seu tempo, o século XIX, empenhou-se na defesa renhida da mais infame das instituições:

A escravidão se apresenta hoje ao nosso espírito sob um aspecto repugnante. Esse fato do domínio do homem sobre o homem revolta a dignidade da criatura racional. Sente-se ela rebaixada com a humilhação de seu semelhante. $O$ cativeiro não pesa unicamente sobre um certo número de indivíduos, mas sobre a humanidade, pois uma porção dela acha-se reduzida ao estado de coisa. Mais bárbaras instituições, porém, do que a escravidão já existiram e foram respeitadas por nações em virtude não somenos às modernas. Não se envergonharam elas em tempo algum de terem laborado no progresso do gênero humano, explorando uma ideia social. Ao contrário, ainda agora lhes são títulos de glória essas leis enérgicas e robustas, que faziam sua força e serviam de músculo a uma raça pujante. Houve jamais tirania comparável ao direito quirital dos romanos? Entretanto foi essa instituição viril que cimentou a formidável nacionalidade do povo rei e fundou o direito civil moderno. Que mais opressivo governo do que o feudalismo? Saiu dele, não obstante, por uma feliz transformação, o modelo da liberdade política, o sistema representativo. É, pois, um sentimento injusto e pouco generoso o gratuito rancor às instituições que deixaram de existir ou estão expirantes. Toda a lei é justa, útil, moral, quando realiza um melhoramento na sociedade e apresenta uma nova situação, embora imperfeita da humanidade. Neste caso está a escravidão.

Evidentemente que o diálogo com o passado não precisa se pautar pelo cancelamento retroativo dos envolvidos. O fundamental pode estar em outro lugar, quem sabe naquilo que foi escondido: a fragilidade de uma retórica de ocasião usada para justificar o que sempre foi injustificável. Assim como há crimes imprescritíveis, há atos que não podem ser desculpados com o álibi do anacronismo. Escravizados sempre souberam que era infame ser reduzido à condição de propriedade e de mercadoria. A estratégia argumentativa de José de Alencar consistia em comparar o pior com o pior e daí extrair resultados sem nexos causais positivos do tipo A produziu B como se o melhor só pudesse ter sido gerado pelo pior. Para o escritor, que também figurou como deputado, tendo votado contra a Lei do Ventre Livre, em 1871 (ver SILVA, 2017), e ministro da Justiça, se depois do horror sobrevém algo salutar, deve-se 
atribuir ao primeiro os méritos pela evolução alcançada.

Alencar (2009, p. 289) olhava no retrovisor para tentar impor ao futuro as supostas vantagens de um presente abominável e resistente:

Sem a escravidão africana e o tráfico que a realizou, a América seria ainda hoje um vasto deserto. A maior revolução do universo, depois do dilúvio, fora apenas uma descoberta geográfica, sem imediata importância. Decerto, não existiriam as duas grandes potências do novo mundo, os Estados Unidos e o Brasil. A brilhante civilização americana, sucessora da velha civilização europeia, estaria por nascer.

Ao tomar o dado como necessário, não abrindo espaço para outras possibilidades, o escritor transformava em benesse o que havia sido abuso. Cometia também o erro de considerar "vasto deserto" um continente habitado por milhões de pessoas, com suas culturas, civilizações e imaginários. Por imaginário, entendam-se as ficções coletivas que estruturam a vida comum. Alencar (2009) pode ser absolvido como "homem do seu tempo" ou condenado por não ter visto um palmo adiante desse tempo ou mesmo conforme o que já sustentavam os seus oponentes. Se intelectual é aquele que sai do seu campo de especialização para atuar no campo dos amplos interesses públicos, ele foi intelectual, mas, como se verá, de um tipo bastante comum e recorrente. Saiu da literatura, onde foi admirado, e atuou na política e nos debates públicos. Defendeu ideias e atacou opositores. Não se furtou ao confronto, aprendeu a discursar e usou o seu prestígio de artista para tentar influenciar os seus contemporâneos, inclusive o imperador D. Pedro II. Não conseguiu, porém, dar o grande salto para compreender a ideia principal em discussão: um ser humano não pode ser reduzido à condição de mercadoria.

\section{Passado sempre presente}

Esse passado já acabou ou ainda se infiltra no presente? Para responder a essa questão é preciso recorrer aos rastros que o passado deixa na sua trilha contra o desaparecimento. É importante salientar que, na época de José de Alencar, havia uma percepção nítida dos horrores da escravidão. O forte da luta pela abolição aconteceria entre 1870 e 1888. Mas mesmo antes disso já existiam reações ao edifício racista que sustentava a economia nacional e alimentava uma classe branca ociosa (SILVA, 2017).

Em O abolicionismo [1883], Joaquim Nabuco (2000) dispôs a questão das relações de 
trabalho na sociedade escravista brasileira em termos profundamente realistas. A cada um, conforme o seu lugar na cadeia social:

Tudo o que significa luta do homem com a natureza, conquista do solo para a habitação e cultura, estradas e edifícios, canaviais e cafezais, a casa do senhor e a senzala dos escravos, igrejas e escolas, alfândegas e correios, telégrafos e caminhos de ferro, academias e hospitais, tudo, absolutamente tudo que existe no país, como resultado do trabalho manual, como emprego de capital, como acumulação de riqueza, não passa de uma doação gratuita da raça que trabalha à que faz trabalhar (NABUCO, 2000, p. 15).

Se na visão dos escravistas isso devia ser visto como normal e proveitoso para todos, como havia dito José de Alencar em seus discursos e cartas a D. Pedro II, gerando riqueza e transformação da natureza em artifícios a serviço dos homens, especialmente os brancos, para Joaquim Nabuco (2000, p. 3), esse estado das coisas representava uma ignomínia:

Essa obra - de reparação, vergonha ou arrependimento, como a queiram chamar - de emancipação dos atuais escravos e seus filhos é apenas a tarefa imediata do abolicionismo. Além dessa, há outra maior, a do futuro: a de apagar todos os efeitos de um regime que, há três séculos, é uma escola de desmoralização e inércia, de servilismo e irresponsabilidade para a casta dos senhores, e que fez do Brasil o Paraguai da escravidão.

Quando uma só pessoa, em determinada época, percebe que determinado valor social é apenas uma impostura, uma racionalização para encobrir interesses infames e imorais, já não será possível posteriormente falar em anacronismo. No caso da escravidão no Brasil, muitas vozes se levantaram ao longo do tempo denunciando a excrescência que servia de alicerce para a economia do país. Embates ideológicos foram travados incansavelmente. Estaria um José de Alencar convencido do que dizia ou mentia abertamente em nome de uma engrenagem econômica e social, como um ateu funcionalista que defende a existência de Deus para não abalar os fundamentos comunitários e não prejudicar a produção de riquezas? Imaginar que Alencar era um cínico o absolveria da possível ingenuidade. Como podia não ver o que outros viam?

Uma hipótese bastante razoável tem a ver com o conceito de ideologia. Trata-se de uma especulação até bastante cômoda. José de Alencar foi "intelectual orgânico" da aristocracia agrícola brasileira. Atuou em prol dos interesses de uma camada apegada a um modo de organização social que custou a perceber os ventos da mudança histórica. São Paulo compreendeu antes de 1888 que o escravismo estava perdido e tratou de apostar na imigração 
para substituir a mão de obra que perderia. O Rio de Janeiro foi menos poroso. O senador Paulino de Souza atacaria a proposta que ganharia o nome de Lei Áurea como “inconstitucional, antieconômica e desumana” (Apud SILVA, 2017, p. 28). Era o último grito dos desesperados. Alencar, portanto, falecido em 1877, pode ser visto como o mais famoso "intelectual orgânico" das classes ociosas do seu tempo. Afinal, como disse o italiano Gramsci $(1979$, p. 3):

Cada grupo social, nascendo no terreno originário de uma função essencial no mundo da produção econômica, cria para si, ao mesmo tempo, de um modo orgânico, uma ou mais camadas de intelectuais que lhe dão homogeneidade e consciência da própria função, não apenas no campo econômico, mas também no social e no político [...] A escola é o instrumento para elaborar os intelectuais de diversos níveis. A complexidade da função intelectual nos vários Estados pode ser objetivamente medida pela quantidade das escolas especializadas e pela sua hierarquização.

Por que Joaquim Nabuco, branco e de família rica, originário da elite agrária pernambucana, não seguiu o mesmo caminho? Terá sofrido influência da vida que levou quando menino, deixado para trás, em Pernambuco, pelos pais, que se mudaram para o Rio de Janeiro, tendo sido criado pela madrinha em fraterna convivência com meninos escravizados nas brincadeiras de todo santo dia? Quem sabe realmente como se formam as visões de mundo de cada um? Quem pode resolver esse mistério das inclinações ideológicas? A ideologia de Joaquim Nabuco ajudou a vencer a escravidão. Ele saiu vitorioso em 1888. A ideologia de José de Alencar disseminou-se encobrindo o passado, fundamentando preconceitos, contaminando o futuro, eliminadas as marcas autorais, capilarizando-se como um infeliz patrimônio comum. Não fosse ele, seria outro? Possivelmente. Muitos foram esses outros que defenderam os benefícios da escravidão e tentaram vê-la como um acidente histórico necessário e frutífero.

José de Alencar (1829-1877) e Joaquim Nabuco (1849-1910) eram de gerações diferentes. Ambos tiveram sucesso em suas atividades. Atuaram na imprensa. Foram "midiáticos". Os seus percursos foram opostos quanto ao grande tema do tempo em que viveram: a escravidão. Para Alencar (2009, p. 283), a abolição era coisa de radicais, uma ameaça comunista:

Decorar com o nome pomposo de filantropia o ideal da ciência e lançar o odioso sobre as instituições vigentes, qualificando seus defensores de 
espíritos mesquinhos e retrógrados, é um terrível precedente em matéria de reforma. Tolerado semelhante fanatismo do progresso, nenhum princípio social fica isento de ser por ele atacado e mortalmente ferido. A mesma monarquia, senhor, pode ser varrida para o canto entre o cisco das ideias estreitas e obsoletas. A liberdade e a propriedade, essas duas fibras sociais, cairiam desde já em desprezo ante os sonhos do comunismo.

Alencar negava a ciência e o progresso em nome da tradição e dos interesses econômicos legalizados. Já Nabuco afirmaria sem pestanejar, com a verve que lhe era peculiar e que fez dele um polemista temível. Note-se que Nabuco não praticava o insulto gratuito, a tirada afrontosa, mas a retórica densa, quase condoreira, intensa, aliando racionalidade e emoção:

No processo do Brasil, um milhão de testemunhas hão de levantar-se contra nós, dos sertões da África, do fundo do oceano, dos barracões da praia, dos cemitérios das fazendas, e esse depoimento mudo há de ser mil vezes mais valioso para a história do que todos os protestos de generosidade e nobreza da alma da nação inteira (NABUCO, 2000, p. 77).

O que dizer mais? A história já fez as contas. A dívida, porém, jamais foi paga. Se há quem espere ingenuamente do conhecimento do passado a sabedoria do presente e a iluminação do futuro, a frustração nunca falha. Mesmo assim, o desafio permanece: não repetir erros, tentar compreender a complexidade dos processos socais, avançar no sentido de respeitar a humanidade do ser humano sem o retirar da sua condição de parte da natureza. $\mathrm{O}$ embate continua. De um lado, os que desejariam sepultar de vez esse passado incômodo. De outro lado, aqueles que insistem em lembrar, em pesquisar, em contextualizar, em praticar essa dialógica do descobrimento pela qual o encoberto vem à luz como uma lufada de ar fresco.

\section{Dinâmica do preconceito na imprensa do século XIX}

$\mathrm{Na}$ luta pela abolição da escravatura no Brasil, muitos foram os jornais que se engajaram. Quem poderia pedir imparcialidade e neutralidade em relação à tamanha infâmia! Passar-se por imparcial ou por neutro, ainda que essas categorias fossem estranhas ao jornalismo do século XIX, seria antiético e imoral. Um exemplo de jornal abolicionista foi $A$ Redempção (1887-1899), criado e sustentado por Antônio Bento, o homem branco que ajudou em fugas de escravos enviados para o quilombo de Jabaquara (localizado em Santos, São 
Paulo).

Para ilustrar como atuavam os jornais nos conturbados anos 1880 do Império basta comparar publicações. Mesmo um jornal liberal como A Província do Espírito Santo (BARROS, 2007), fundado em 1882, podia publicar textos de conteúdo altamente duvidoso ou escancaradamente preconceituoso. É o caso de uma espécie de crônica racista exposta na primeira página da edição de 11 de setembro de 1887, a "Lenda da criação do preto" (SILVA, 2017):

\begin{abstract}
No tempo da criação do mundo, Satanás vendo o Padre Eterno criar Adão, de um pedaço de barro, quis também fazer o mesmo. Satanás pegou num pedaço de argila, deu-lhe as mesmas voltas que vira dar-lhe Deus, e depois insuflou-lhe a vida num sopro. Mas com grande espanto e com grande raiva sua, esse bocado de barro, como tudo o mais que ele tocava, ficou negro: - o seu homem era um homem preto. Ali ao pé corria límpido e transparente o branco rio Jordão. Satanás teve uma ideia, lavar o seu homem para lhe tirar a negrura. E [Satanás] pegou nele pela cintura como se pega num cachorro e mergulhou-o no rio. Mas as águas do Jordão afastaram-se imediatamente, enojadas com aquela negrura, e o homem de Satã, o primeiro negro, apenas mergulhou os pés e as mãos no lodo. E por isso só as palmas das mãos e dos pés ficaram brancas. Furioso com o seu desastre, Satanás perdeu a cabeça, e pespegou um famoso murro na cara do seu negro que lhe achatou o nariz e lhe fez inchar os lábios. O desgraçado preto pediu misericórdia, e Satanás, passado o primeiro momento de fúria, compreendendo que no fim das contas o negro não tinha nenhuma culpa de ser assim, teve dó dele, arrependeu-se de repente do seu gênio e acariciou, passando-lhe a mão pela cabeça. Mas a mão do diabo queima tudo em que toca: crestou o cabelo do negro como se os seus dedos fossem ferro de frisar. E foi daí que o preto ficou com carapinha. Se non é vero...
\end{abstract}

Não é preciso fazer muito esforço hermenêutico para compreender o teor racista do texto. O homem branco seria criação de Deus; o preto, do diabo. Todos os aspectos físicos costumeiramente usados para ofender pessoas negras, como se fossem elementos desqualificadores, são apresentados. Embora as tiragens do jornal fossem pequenas, num universo de minoria alfabetizada, pode-se imaginar a repercussão causada. $\mathrm{O}$ veículo, mesmo sendo favorável a reformas liberais e tendo apoiado a aprovação da Lei dos Sexagenários (1885), permitia-se difundir preconceitos como se fosse apenas um leve entretenimento (SILVA, 2017). Ser abolicionista não significava necessariamente ser antirracista. Havia de tudo: monarquistas abolicionistas, republicanos escravistas, abolicionistas racistas.

O final do texto, com a expressão italiana "se non é vero", que normalmente se completa com "é bene trovato", parece vincular a escravidão negra e a imigração branca 
europeia num contraponto injurioso. O jornal tratou fartamente do tema da imigração. Um dos argumentos nacionais difundidos para convencer proprietários de escravos da importância da abolição referia-se à superioridade racial dos colonos europeus:

Enquanto os abolicionistas retomavam os argumentos dos emancipacionistas, que desde o início do século pretenderam a incorporação social do negro livre, os imigrantistas consolidavam sua posição quanto à vagabundagem irremediável do ex-escravo e seus descendentes por força de suas supostas origens raciais inferiores (Apud AZEVEDO, 1987, p. 104).

A abolição foi uma luta travada nas ruas, nas lavouras, nos teatros, no parlamento e nos jornais. Folhas de poucas páginas e tiragens mínimas brandiam armas. Talvez nunca se tenha acreditado tanto na força dos argumentos. Nem só, contudo, de argumentos viviam os jornais. Tudo era permitido: atacar, ofender, insultar, emocionar, alfinetar, constranger. $\mathrm{O}$ jornalismo do século XIX não era esporte de combate. Era guerra mesmo. Tendo florescido tardiamente, com a chegada da família real ao Brasil, esse jornalismo nasceu político e com muitas causas para defender ou atacar. O primeiro grande conflito deu-se em torno da independência, do nascimento da nação, da formação do país. O segundo se daria no campo da escravidão: proibição do tráfico, leis gradualistas, abolição. O terceiro teria a ver com a passagem da Monarquia à República. O lento caminho para a abolição exigiu da imprensa resiliência, renovação, coragem e perseverança.

Para $A$ Redempção, toda agressão física a senhor de escravos por um escravizado devia ser vista como legítima defesa. Folha bissemanal "abolicionista, comercial e noticiosa", no primeiro editorial, em 2 de janeiro de 1887, dissera a que vinha e com quem não conciliaria:

O título do nosso jornal já indica a nossa missão na imprensa. Divergimos completamente tanto dos liberais resistentes quanto dos escravocratas, não concordamos com as ideias conservadoras e detestamos aqueles que, trazendo o capacete frígio na cabeça, trazem na mão o bacalhau com que cotidianamente surram os seus míseros escravos (Apud SILVA, 2017, p. 309).

Não conciliaria e não perdoaria. O veículo do católico Antonio Bento era um instrumento visceral de combate, com linguagem coloquial debochada, indiferente às regras do português das classes dominantes pomposas, que enfrentaria a imprensa conservadora, não se furtando a apontar o dedo, a criticar, a ironizar, a ridicularizar os representantes das 
camadas abastadas, que se sustentavam publicando editais de leilões de escravos.

Falamos do aparecimento do jornal A Província de São Paulo, órgão republicano [...] dirigido por três grandes homens [...] Mas como não devemos fazer elogios perfeitos, pois isso vai contra a índole da nossa folha, devemos dizer que $A$ Província não tem descrito como devia e podia fazê-lo a questão do elemento servil. A Província poderia convencer aos fazendeiros especialmente republicanos que a escravidão é roubo, um furto. Pelo contrário, tem falado sobre os quilombos aos quais tem reclamado providências (Apud SCHWARCZ, 1987, p. 94).

Os "jornalões" da época faziam o discurso que ainda pode ser encontrado hoje, em relação aos chamados temas sociais, em páginas que se consideram responsáveis e sérias: pela ordem, pelo respeito sem exceção à lei, mesmo em se tratando da mais infame das leis, pelo estrito respeito aos imperativos econômicos da produção. A cobrança feita por Antonio Bento buscava denunciar uma contradição no jogo político da época, o republicanismo escravista, e definir uma visão de mundo cristalina: a escravidão roubava o trabalho e a liberdade de seres humanos. Nesse sentido, não havia mais espaço para negociações e tergiversações. O tempo da escravidão estava morto. Tratava-se de apresentar o atestado de óbito de uma instituição mantida viva artificialmente. O escravismo, porém, continuava a ser mais do que um espectro andando pelos campos e cidades do país. Era uma realidade que se alimentava de corpos negros.

A proibição do tráfico, em 1850, com a fiscalização do contrabando que fizera a lei de 1831 não pegar, aquela que seria a primeira lei "para inglês ver", levara ao tráfico interprovincial. As províncias cafeeiras compraram os escravizados jovens e fortes das demais. Aquelas que se viram com poucos escravos aceitaram mais facilmente a tendência abolicionista (SILVA, 2017).

\section{Por uma utopia}

Resta a volta da utopia iluminista reinventada: nenhuma discriminação por sexo, cor da pele, religião ou origem social. O iluminismo não sabia que carregava uma contradição: o seu discurso universal abstrato encobriria as separações de fato. Onde não se devia escolher por cor da pele, triunfaram os brancos. Onde não se devia distinguir por gênero, reinaram os homens; e assim sucessivamente. O iluminismo se via como profissão de fé na razão, na ciência e na emancipação do homem. Acabou por ser a ideologia do colonialismo, uma 
cobertura para o etnocentrismo, a visão de mundo do homem branco heterossexual europeu. A razão virou racionalismo árido e sufocante. Sufocou o não racional, o emocional, o simbólico. Até que se inclinou.

Os marginalizados, tornados invisíveis historicamente, secundarizados, subalternizados, estão virando o jogo. As marcas do colonialismo são denunciadas implacavelmente a cada dia. Um novo imaginário está em produção. Cada impulso com seus ganhos e perdas. Em oposição ao absolutismo moderno da pretensa racionalidade triunfante ergueu-se um relativismo primeiramente prudente, depois ousado, por fim, absoluto. Se havia verdades definitivas em demasia, nunca provadas, passou a não mais existir qualquer verdade, tudo não passando de narrativas, de construções, de ideologias não percebidas ou dissimuladas. E assim, num salto acrobático, caricatural, voltou a tese da Terra plana e com ela outras negações mais ou menos obscurantistas, contra a qual já se levanta um novo discurso em defesa da ciência, da verdade e da demonstração empírica.

A escravidão não foi praticada pelo bem dos escravizados. Esses homens e mulheres não foram comprados na África para que suas almas fossem "resgatadas" do paganismo. José de Alencar não era o imparcial defensor dos progressos da civilização ocidental por meio de dispositivos condenáveis, mas úteis e desculpáveis. A escravidão no Brasil, como mostrou Joaquim Nabuco (2000), serviu a uma classe ociosa branca disposta a tudo para manter seus privilégios pelo maior tempo possível. A imprensa dividiu-se. Por vezes, mesmo uma imprensa pretensamente emancipacionista podia vender espaços para a divulgação de leilões de escravizados ou para anúncios de fugas de escravos. Aqueles que adotaram posturas mais firmes, como A Redempção, foram rotulados de radicais e extremistas. O imaginário da retórica não aparece acompanhar as transformações tecnológicas. Há uma tendência a conservação das categorias de acusação, dos insultos e das contradições.

A escravidão foi uma operação capitalista. No século XVI, a taxa de retorno das ações no tráfico era de 6\% ao ano (SILVA, 2017). Um belo negócio para quem não se perdia em dilemas éticos. O racismo não foi a causa, mas a consequência disso. A "banalidade do mal" nazista foi precedida pela banalidade da ganância capitalista, que inventou o racismo contra os africanos para legitimar e naturalizar o comércio que ceifou milhões de vida. Era só um bom negócio com carne humana encontrada com fartura na África. No século XIX, a ciência capitalista inventou teorias raciais para tentar justificar o direito dos brancos de dominar os 
negros. Não durou para sempre. Mas provocou enormes estragos cujos efeitos ainda se fazem sentir.

A história da acumulação primitiva do capitalismo é a verdadeira história universal da infâmia. Os mais otimistas, ou cínicos, garantem que esse foi o preço pago pela liberdade atual. Falso. O passado dessa mercadoria altamente rentável que foi o negro ainda pode ser reciclado em filmes de Hollywood. O lucro é alto. No Brasil, o escravista José de Alencar (2009, p. 293), em carta ao imperador D. Pedro II, perguntava: “É a escravidão um princípio exausto, que produziu todos os seus bons efeitos e tornou-se, portanto, um abuso, um luxo de iniquidade e opressão?" Ele mesmo respondia com desenvoltura e convicção de não errar por se sentir sábio: "Nego, senhor, e o nego com a consciência do homem justo, que venera a liberdade; com a caridade do cristão, que ama seu semelhante e sofre na pessoa dele" (ALENCAR, 2009, p. 293). Define: "Afirmo que o bem de ambas, da que domina como da que serve, e desta principalmente, clama pela manutenção de um princípio que não representa somente a ordem social e o patrimônio da nação; mas, sobretudo, encerra a mais sã doutrina do evangelho" (ALENCAR, 2009, p. 293).

Não é possível deixar de pensar nisso quando se reflete, na manhã incendiada pelo sol da modernidade, sobre escolhas, liberdade, livre arbítrio e todas essas belas palavras usadas pelos homens durante tanto tempo que quase perderam o sentido.

\section{Referências}

ALENCAR, José de. Cartas de Erasmo. Rio de Janeiro: ABL, 2009.

AZEVEDO, Celia Maria Marinho de. Onda negra, medo branco: o negro no imaginário das elites século XIX. Rio de Janeiro: Paz e Terra, 1987.

BARROS, Thiago Zanetti de. Imigração estrangeira no jornal A Província do Espírito Santo (1882/1889). Dissertação (Mestrado em História) - Programa de Pós-graduação em História Social das Relações Políticas, Universidade Federal do Espírito Santo (UFES), Vitória, 2007.2 Disponível em: https://ape.es.gov.br/Media/ape/PDF/Disserta\%C3\%A7\%C3\%B5es\%20e\%20Teses/Hist $\% \mathrm{C} 3$ \%B3ria-UFES/UFES_PPGHIS_THIAGO_ZANETTI_BARROS.pdf. Acesso em: 20 maio 2021.

GRAMSCI, Antonio. Os intelectuais e a organização da cultura. Rio de Janeiro: Civilização Brasileira, 1979. 
MORIN, Edgar. O método 6: ética. Porto Alegre: Sulina, 2005.

NABUCO, Joaquim. O abolicionismo. Rio de Janeiro: Nova Fronteira: 2000.

SCHWARCZ, Lilia Moritz. Retrato em branco e negro. Jornais, escravos e cidadão em São Paulo no final do século XIX. São Paulo: Companhia das Letras, 1987.

SILVA, Juremir Machado da. Raízes do conservadorismo brasileiro - a abolição na imprensa e no imaginário social. Rio de Janeiro: Civilização Brasileira, 2017.

Autor convidado. 